\title{
Geographic Variations and Time Trends in Cancer Treatments in Taiwan
}

\author{
Jason C. Hsu ${ }^{1 *}$, Sheng-Mao Chang ${ }^{2}$ and Christine Y. Lu ${ }^{3}$
}

\begin{abstract}
Background: Targeted therapies have become important treatment options for cancer care in many countries. This study aimed to examine recent trends in utilization of antineoplastic drugs, particularly the use of targeted therapies for treatment of cancer, by geographic region in Taiwan (northern, midwestern, southern, and eastern regions and the outer islands).

Methods: This was a retrospective observational study of antineoplastic agents using 2009-2012 quarterly claims data from Taiwan's National Health Insurance Research Database. Yearly market shares by prescription volume and costs for targeted therapies among total antineoplastic agents by region were estimated. We used multivariate regression model and ANOVA to examine variations in utilization of targeted therapies between geographic regions and used ARIMA models to estimate longitudinal trends.

Results: Population-adjusted use and costs of antineoplastic drugs (including targeted therapies) were highest in the southern region of Taiwan and lowest in the outer islands. We found a 4-fold difference in use of antineoplastic drugs and a 49-fold difference in use of targeted therapies between regions if the outer islands were included. There were minimal differences in use of antineoplastic drugs between other regions with about a 2-fold difference in use of targeted therapies. Without considering the outer islands, the market share by prescription volume and costs of targeted therapies increased almost 2-fold (1.84-1.90) and 1.5-fold (1.26-1.61) respectively between 2009 and 2012. Furthermore, region was not significantly associated with use of antineoplastic agents or use of targeted therapies after adjusting for confounders. Region was associated with costs of antineoplastic agents but it was not associated with costs of targeted therapies after confounding adjustments.
\end{abstract}

Conclusions: Use of antineoplastic drugs overall and use of targeted therapies for treatment of cancer varied somewhat between regions in Taiwan; use was notably low in the outer islands. Strategies might be needed to ensure access to cancer care in each region as economic burden of cancer care increase due to growing use of targeted therapies.

Keywords: Cancer, Targeted Therapy, Geographic regions, Taiwan

\section{Background}

Knowledge of etiology and epidemiology of cancer has great importance for control of cancer, which is a major public health issue across the world due to its high mortality and increasing prevalence $[1,2]$. Over the past few decades, a considerable number of studies have examined factors associated with the occurrence, treatment and outcomes of specific cancer type in many countries [3-5]. Demographic characteristics (including hereditary genetic mutations, age, gender, ethnicity, education, and geographic

\footnotetext{
* Correspondence: jasonhsuharvard@gmail.com

${ }^{1}$ School of Pharmacy and Institute of Clinical Pharmacy and Pharmaceutical Sciences, College of Medicine, National Cheng Kung University, No.1, Daxue Rd., East Dist., Tainan 70101, Taiwan

Full list of author information is available at the end of the article
}

location), environmental hazards (such as exposure to radiation, smoking, and pollutions), patient health status and behavior (e.g., diet, obesity, physical activity, history of disease, comorbidity and drug use), and health care providers' characteristics (e.g., physicians' knowledge and preferences, prescribing patterns, clinical guidelines and economical considerations) may contribute to variations in cancer incidence, diagnosis, treatment and outcomes between regions [6, 7]. Better understanding of factors influencing cancer diagnosis and treatments can allow us to improve quality of cancer care and outcomes and facilitate health policy planning.

In the last few years, several studies have assessed the association between geographic variation and incidence 
of cancer [8-12]. For instance, a US study [12] found that incidence of colorectal cancer was highest in the Middle Atlantic division, with the lowest rate observed in the Mountain division. Researchers have investigated cancer screening or diagnosis in various geographic locations, and found geographic variations in the uptake of screening and diagnosis of several cancers including cervical, lung and liver cancers [13-15]. Such geographical differences have increased during the past decade in many countries, including Taiwan [13-17]. Cancer treatment and cancer care also vary between geographic locations [10, 18-21]. For example, Reames et al. [21] reported wide geographic variations in utilization of laparoscopic colectomy among US Medicare patients with colon cancer (from 0\% to 66.8\% across 306 hospital referral regions). Furthermore, the association between geographic variation and clinical outcomes (such as survival and mortality) of cancer treatment has been investigated extensively [8, 9, 22, 23]. Andia et al. [23] indicated that gallbladder cancer mortality rate was higher in the inland and southern regions of Chile, and compared to the north-coastal region, the northern-inland region had a 10 -fold higher risk and the southern-inland region had a 26-fold higher risk.

There has been an increasing availability and use of targeted therapies for treatment of cancer due to their high treatment response rates $[24,25]$ but less toxic characteristics compared with traditional chemotherapies [26]. For several cancers, targeted therapies are becoming the main treatments; examples include erlotinib for lung cancer [27-29] and trastuzumab for breast cancer [30, 31]. With the growing trends in use of targeted therapies, the burden of pharmaceutical expenditure due to their high costs and their accessibility, have lately become one of the most serious concerns in all countries with universal health insurance systems, including Taiwan's national health insurance system. Taiwan's national health insurance system is a compulsory social insurance system in which the coverage rate of its 23 million residents is as high as $99 \%$ currently [32].

Previous research has not addressed whether or not the use of targeted therapies for treatment of cancer differs from region to region in Taiwan [33, 34]. To provide insights about the accessibility and equity issues related to high-cost targeted therapies, we examined use and costs of antineoplastic agents by geographic region (northern, midwestern, southern, and eastern regions, and the outer islands) in Taiwan, particularly focusing on cancer targeted therapies.

\section{Method}

\section{Data sources}

This study used nationwide claims data from the National Health Insurance Research Database (NHIRD), which compiles data of over $99 \%$ of population (around 23 million residents) in Taiwan. The database contains information from a mandatory-enrollment and single-payer healthcare system created in 1995, and it covers a wide range of prescription medicines, and inpatient and outpatient medical services [35]. We obtained 2009-2012 quarterly claims data from NHIRD regarding treatment of malignancies, including details of prescriptions and national health insurance expenditure for antineoplastic agents. The cancer related prescriptions were identified using International Classification of Diseases, $9^{\text {th }}$ edition (ICD-9) diagnosis codes (codes: 140-239). We converted costs in Taiwan dollars to US dollars by $30: 1$. Our previous studies also used this data source $[36,37]$. In addition, yearly population data by age and region, yearly geographical area by region, yearly number of physician by region were obtained from the Department of Statistics, Taiwan Ministry of Interior [38]. We obtained population statistics and cancer incidence from Taiwan Cancer Registry Annual Report [39].

\section{Drugs included}

We used World Health Organization's Anatomical Therapeutic Chemical (ATC) classification system to identify antineoplastic agents (with code "L01"). We grouped antineoplastic agents into 6 classes based on the ATC system: [1] targeted therapies (including monoclonal antibodies, protein kinase inhibitors and other targeted therapies). Among targeted therapies: monoclonal antibodies (rituximab, trastuzumab, and cetuximab), protein kinase inhibitors (imatinib, gefitinib, erlotinib, sunitinib, sorafenib, dasatinib, nilotinib, temsirolimus, everolimus, and pazopanib), and bortezomib have been used for the treatment of cancer in Taiwan; [2] alkylating agents (including nitrogen mustard analogues, alkyl sulfonates, nitrosoureas and other alkylating agents); [3] antimetabolites (including folic acid analogues, purine analogues and pyrimidine analogues); [4] plant alkaloids and other natural products (including vinca alkaloids and analogues, podophyllotoxin derivatives and taxanes); [5] cytotoxic antibiotics and related substances (including actinomycines, anthracyclines and related substances and other cytotoxic antibiotics); and [6] other agents (including platinum compounds, sensitizers used in photodynamic/radiation therapy and others).

\section{Outcome measures}

We calculated quarterly and yearly number of prescriptions and costs from 2009 to 2012 to examine the use and costs of each class of antineoplastic agents. We used administrative divisions of Taiwan to group utilization and costs according to the 5 regions: northern, midwestern, southern, and eastern regions and the outer islands (Appendix 1). To assess regional differences, we estimated population-adjusted number of targeted therapies prescription and costs (per 100,000 people) for each region. For each region, population-adjusted prescription 
volume was calculated by using number of prescriptions divided by number of population in that region, and population-adjusted costs was calculated by using total costs divided by number of population in the region. Because cancer incidence by year and across regions was overall stable (Appendix 2), we presented populationadjusted results by region.

We also calculated the yearly market shares by prescription volume and by costs for targeted therapies among total antineoplastic agents. Market share by prescription volume was estimated by: number of prescriptions for targeted therapies divided by total number of prescriptions for all antineoplastic agents. The market share by costs was estimated by: costs of targeted therapies divided by total costs of all antineoplastic agents.

\section{Statistical Analysis}

We used univariate and multivariate regression models and analysis of variance (ANOVA) to examine the association between 'region' and population-adjusted use and costs of antineoplastic agents. In separate models, we assessed the association between 'region' and populationadjusted use and costs of targeted therapies. We only focused on four regions - northern, midwestern, southern and eastern regions; we excluded the outer islands in these models because its use of antineoplastic agents was much lower than that in other regions. Our models controlled for the following covariates: average age of cancer patients in that region, percentage of male cancer patients in that region, population density (number of population divided by geographic area), physician density (number of physician divided by number of population in the region * 100,000 people), and cancer incidence per 100,000 population. We also used a time series design with the Autoregressive integrated moving average (ARIMA) model $[40,41]$ to estimate longitudinal trends in targeted therapy use and costs. All analyses were carried out with SAS software, Version 9.3 (SAS Institute, Cary, NC).

\section{Results}

\section{Regional variations}

Between 2009 and 2012, we observed steady increases in use of all antineoplastic drugs in all regions (ranged from 1.33 to 1.56 -fold increase in population-adjusted prescription volume). Use of cancer targeted therapies also more than doubled in all regions except the outer islands (ranged from 2.47 to 2.54 -fold increase in population-adjusted prescription volume across regions without considering the outer islands). Table 1 presents use and costs by region across years. In 2012, there was a 4.20-fold difference in population-adjusted use of all antineoplastic drugs between the southern region (highest) and the outer islands (lowest) but a 49.11-fold difference in population-adjusted use of targeted therapies between the southern region (highest) and the outer islands (lowest). Without considering the outer islands, there was a 1.25 -fold difference in population-adjusted use of antineoplastic drugs between the southern region and the eastern region and a 1.89-fold difference in population-adjusted use of targeted therapies between the southern region and the eastern region in 2012.

Similarly, population-adjusted costs of all antineoplastic drugs increased from 2009 to 2012 in all regions (ranged from 1.48 to 2.35 -fold increase in population-adjusted costs). Costs of cancer targeted therapies also more than doubled in most regions (ranged from 1.91 to 2.56-fold increase in population adjusted costs across regions without considering the outer islands). In 2012, there was a 9.00fold difference in population-adjusted costs of antineoplastic drugs between the southern region (highest) and the outer islands (lowest) and a 74.74-fold difference in population-adjusted costs of targeted therapies between the southern region (highest) and the outer islands (lowest). Without considering the outer islands, there was a 1.36 -fold difference in population-adjusted costs of antineoplastic drugs between the southern region and the eastern region and a 1.66-fold difference in population-adjusted costs of targeted therapies between the southern region and the eastern region in 2012.

Results from univariate and multivariate regression models (without considering the outer lands) are shown in Tables 2 and 3. For antineoplastic agents, year and region were significantly associated with their costs but they were not associated with the use of these drugs, after adjusting for covariates. Using the southern region as the reference, there was no significant difference in use of antineoplastic agents between regions, but their costs were significantly lower in other regions. Average age of cancer patients, percentage of male cancer patients, and population density were also significantly and positively associated with costs of antineoplastic drugs. For targeted therapies in particular, year and region were not significantly associated with their use although year was associated with their costs. Using the southern region as the reference, there was no significant difference in use and costs of targeted therapies between regions. Percentage of male cancer patients was significantly and positively associated with use and costs of targeted therapies.

\section{Market share of targeted therapies}

Apart from the outer islands, the market share of targeted therapies by prescription volume for northern, midwestern, southern, and eastern regions of Taiwan was around 5\% (4.42\% 6.70\%) in 2012, but they accounted for over $25 \%$ of costs for all antineoplastic agents (Table 4). The yearly market share of targeted therapies by prescription volume for each region increased almost 2-fold (1.841.90) between 2009 and 2012 without considering the outer 


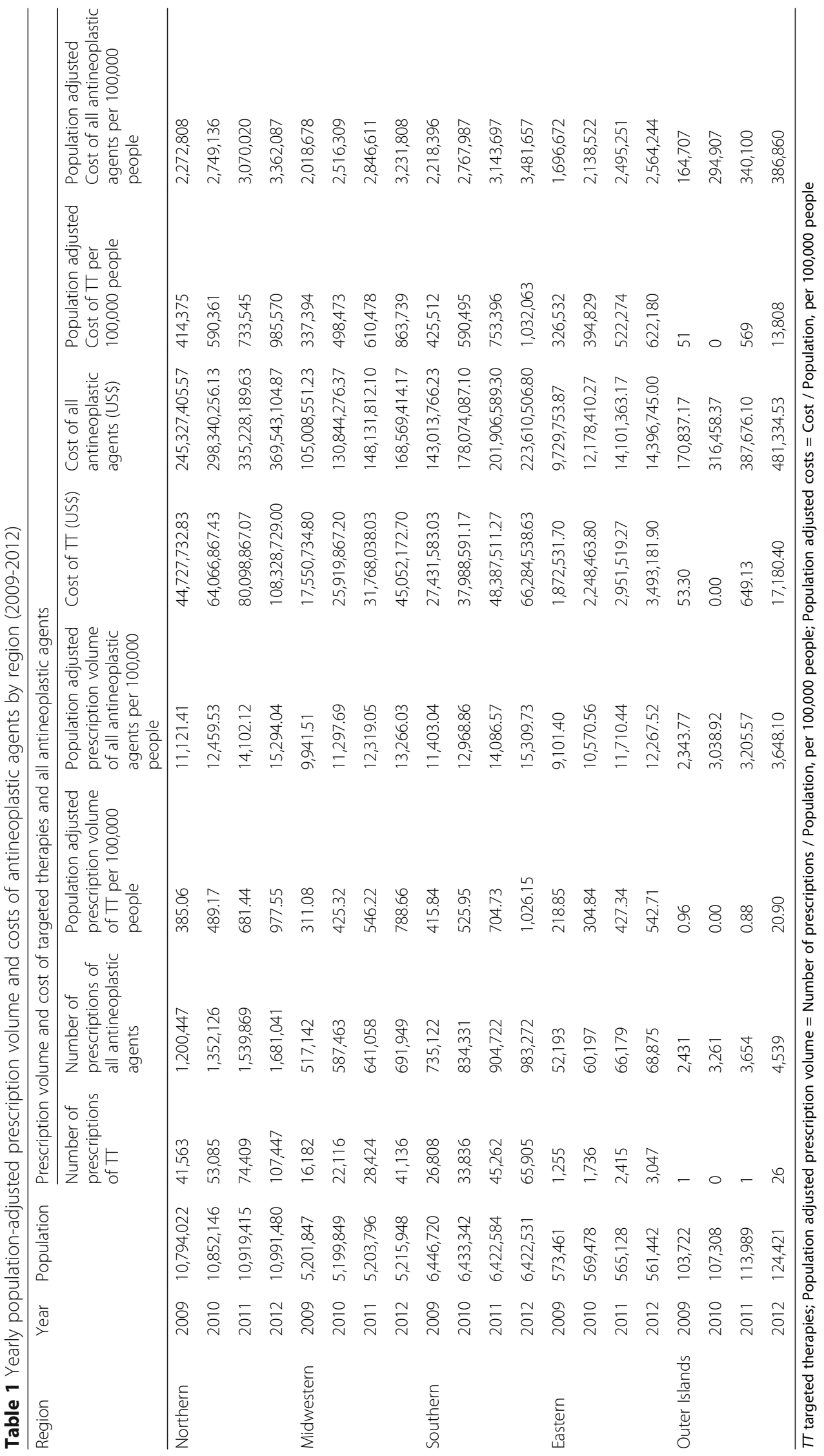


Table 2 Results of ANOVA assessing association between region and use and costs of antineoplastic agents in Taiwan

\begin{tabular}{|c|c|c|c|c|c|}
\hline Dependent Variable & Independent Variables and Confounders & Unadjusted F & $P$-value & Adjusted F & $P$-value \\
\hline \multicolumn{6}{|c|}{ Population adjusted prescription volume of antineoplastic agents per 100,000 people } \\
\hline & Region & 100.019 & $<0.001$ & 3.456 & 0.131 \\
\hline & Year & 166.477 & $<0.001$ & 1.672 & 0.309 \\
\hline & Average Age & & & 0.473 & 0.529 \\
\hline & $\%$ of Male & & & 1.869 & 0.243 \\
\hline & Population density & & & 0.297 & 0.615 \\
\hline & Physician density & & & 0.352 & 0.585 \\
\hline & Cancer incidence & & & 0.003 & 0.959 \\
\hline \multicolumn{6}{|c|}{ Population adjusted cost of antineoplastic agents per 100,000 people } \\
\hline & Region & 61.595 & $<0.001$ & 13.735 & 0.014 \\
\hline & Year & 145.303 & $<0.001$ & 132.461 & $<0.001$ \\
\hline & Average Age & & & 64.382 & 0.001 \\
\hline & $\%$ of Male & & & 93.412 & 0.001 \\
\hline & Population density & & & 37.111 & 0.004 \\
\hline & Physician density & & & 1.332 & 0.313 \\
\hline & Cancer incidence & & & 4.128 & 0.112 \\
\hline \multicolumn{6}{|c|}{ Population adjusted prescription volume of TT per 100,000 people } \\
\hline & Region & 19.165 & $<0.001$ & 1.295 & 0.391 \\
\hline & Year & 51.340 & $<0.001$ & 6.103 & 0.057 \\
\hline & Average Age & & & 0.152 & 0.717 \\
\hline & $\%$ of Male & & & 8.368 & 0.044 \\
\hline & Population density & & & 0.546 & 0.501 \\
\hline & Physician density & & & 0.701 & 0.449 \\
\hline & Cancer incidence & & & 0.001 & 0.978 \\
\hline \multicolumn{6}{|c|}{ Population adjusted cost of $\Pi$ per 100,000 people } \\
\hline & Region & 13.449 & 0.001 & 2.557 & 0.193 \\
\hline & Year & 52.473 & $<0.001$ & 16.615 & 0.010 \\
\hline & Average Age & & & 0.263 & 0.635 \\
\hline & $\%$ of Male & & & 18.796 & 0.012 \\
\hline & Population density & & & 0.615 & 0.477 \\
\hline & Physician density & & & 1.471 & 0.292 \\
\hline & Cancer incidence & & & 0.640 & 0.469 \\
\hline
\end{tabular}

$\pi$ targeted therapies; Average Age $=$ average age of cancer patients; $\%$ of Male $=$ percentage of male cancer patients; Population density $=$ number of population divided by geographic area; Physician density = number of physician divided by number of population in that region per 100,000 people; bold and italic $=$ significant

islands. The southern region had the highest market share by prescription volume $(6.70 \%)$ in 2012 , followed by the northern (6.39\%), midwestern (5.94\%), and eastern regions $(4.42 \%)$, and the outer islands $(0.57 \%)$. This represents about 11.70-fold difference between regions if the outer islands were included; without considering the outer islands, there was only a 1.52 -fold difference between regions.

The yearly market share by costs of targeted therapies for each region also grew around 1.5-fold (1.26-1.61) from 2009 to 2012. The southern region had the highest market share by costs (29.64\%) in 2012, followed by the northern (29.31\%), midwestern (26.73\%), and eastern regions (24.26\%), and the outer islands (3.57\%). It represents about 8.30 -fold difference between regions if the outer islands were included; without considering the outer islands, there was only a 1.22-fold difference between regions.

\section{Trends in use of targeted therapies}

We estimated 2009-2012 trends in quarterly market shares by prescription volume and costs for targeted therapies among all antineoplastic agents by region. Figure 1 shows 2009-2012 trends in market share of targeted therapies by prescription volume by region. In the southern region (region with the highest rate in 2012), the quarterly market 
Table 3 Results of multivariate regression model assessing association between region and use and costs of antineoplastic agents in Taiwan

\begin{tabular}{|c|c|c|c|c|c|}
\hline Dependent Variable & Independent Variables and Confounders & Unadjusted $t$ & $P$-value & Adjusted $\mathrm{t}$ & $P$-value \\
\hline \multicolumn{6}{|c|}{ Population adjusted prescription volume of antineoplastic agents per 100,000 people } \\
\hline & Southern region & reference & & reference & \\
\hline & Northern region & -1.146 & 0.281 & -0.565 & 0.602 \\
\hline & Midwestern region & -10.056 & $<0.001$ & -0.733 & 0.504 \\
\hline & Eastern region & -14.653 & $<0.001$ & 0.409 & 0.703 \\
\hline & Year 2012 & reference & & reference & \\
\hline & Year 2011 & -5.676 & $<0.001$ & -1.392 & 0.236 \\
\hline & Year 2010 & -12.803 & $<0.001$ & -1.264 & 0.275 \\
\hline & Year 2009 & -21.100 & $<0.001$ & -1.554 & 0.195 \\
\hline & Average Age & & & -0.688 & 0.529 \\
\hline & $\%$ of Male & & & 1.367 & 0.243 \\
\hline & Population density & & & 0.545 & 0.615 \\
\hline & Physician density & & & 0.593 & 0.585 \\
\hline & Cancer incidence & & & -0.055 & 0.959 \\
\hline \multicolumn{6}{|c|}{ Population adjusted cost of antineoplastic agents per 100,000 people } \\
\hline & Southern region & reference & & reference & \\
\hline & Northern region & -0.703 & 0.500 & -5.797 & 0.004 \\
\hline & Midwestern region & -4.448 & 0.002 & -4.963 & 0.008 \\
\hline & Eastern region & -12.106 & $<0.001$ & -5.519 & 0.005 \\
\hline & Year 2012 & reference & & reference & \\
\hline & Year 2011 & -4.831 & 0.001 & -8.271 & 0.001 \\
\hline & Year 2010 & -10.996 & $<0.001$ & -7.521 & 0.002 \\
\hline & Year 2009 & -19.753 & $<0.001$ & -10.691 & $<0.001$ \\
\hline & Average Age & & & 8.024 & 0.001 \\
\hline & $\%$ of Male & & & 9.665 & 0.001 \\
\hline & Population density & & & 6.092 & 0.004 \\
\hline & Physician density & & & -1.154 & 0.313 \\
\hline & Cancer incidence & & & 2.032 & 0.112 \\
\hline \multicolumn{6}{|c|}{ Population adjusted prescription volume of $\Pi$ per 100,000 people } \\
\hline & Southern region & reference & & reference & \\
\hline & Northern region & -0.811 & 0.438 & -0.726 & 0.508 \\
\hline & Midwestern region & -3.498 & 0.007 & -0.107 & 0.920 \\
\hline & Eastern region & -6.858 & $<0.001$ & 0.567 & 0.601 \\
\hline & Year 2012 & reference & & reference & \\
\hline & Year 2011 & -5.674 & $<0.001$ & -2.343 & 0.079 \\
\hline & Year 2010 & -9.248 & $<0.001$ & -1.388 & 0.238 \\
\hline & Year 2009 & -11.659 & $<0.001$ & -1.247 & 0.281 \\
\hline & Average Age & & & -0.389 & 0.717 \\
\hline & $\%$ of Male & & & 2.893 & 0.044 \\
\hline & Population density & & & 0.739 & 0.501 \\
\hline & Physician density & & & 0.838 & 0.449 \\
\hline & Cancer incidence & & & -0.030 & 0.978 \\
\hline
\end{tabular}


Table 3 Results of multivariate regression model assessing association between region and use and costs of antineoplastic agents in Taiwan (Continued)

\begin{tabular}{|c|c|c|c|c|}
\hline \\
\hline \multicolumn{5}{|l|}{$\begin{array}{c}\text { Population adjusted Cost of TT per 100,000 people } \\
\text { Southern region }\end{array}$} \\
\hline \multicolumn{5}{|l|}{ Northern region } \\
\hline Midwestern region & -2.957 & 0.016 & -0.338 & 0.752 \\
\hline Eastern region & -5.631 & $<0.001$ & 0.489 & 0.650 \\
\hline Year 2012 & \multicolumn{2}{|l|}{ reference } & \multicolumn{2}{|l|}{ reference } \\
\hline Year 2011 & -5.320 & $<0.001$ & -3.813 & 0.019 \\
\hline Year 2010 & -8.603 & $<0.001$ & -2.238 & 0.089 \\
\hline Year 2009 & -12.036 & $<0.001$ & -2.323 & 0.081 \\
\hline & \multicolumn{2}{|c|}{ Average Age } & 0.512 & 0.635 \\
\hline & \multicolumn{2}{|c|}{$\%$ of Male } & 4.335 & 0.012 \\
\hline & \multicolumn{2}{|c|}{ Population density } & 0.784 & 0.477 \\
\hline & \multicolumn{2}{|c|}{ Physician density } & 1.213 & 0.292 \\
\hline & \multicolumn{2}{|c|}{ Cancer incidence } & -0.800 & 0.469 \\
\hline
\end{tabular}

$\pi$ targeted therapies; Average Age $=$ average age of cancer patients; $\%$ of Male $=$ percentage of male cancer patients; Population density $=$ number of population divided by geographic area; Physician density = number of physician divided by number of population in that region per 100,000 people; bold and italic = significant

Table 4 Yearly market share by prescription volume and costs of antineoplastic agents by region (2009-2012)

\begin{tabular}{|c|c|c|c|c|c|c|c|c|}
\hline \multirow[t]{2}{*}{ Region } & \multirow[t]{2}{*}{ Year } & \multicolumn{7}{|c|}{ Market share by prescription volume and Costs of targeted therapies } \\
\hline & & Population & $\begin{array}{l}\text { Number of } \\
\text { prescription } \\
\text { for } \pi\end{array}$ & $\begin{array}{l}\text { Number of prescription } \\
\text { for all antineoplastic } \\
\text { agents }\end{array}$ & $\begin{array}{l}\text { Market share } \\
\text { by prescription } \\
\text { volume (\%) }\end{array}$ & Cost of $\Pi$ (US\$) & $\begin{array}{l}\text { Cost of all } \\
\text { antineoplastic } \\
\text { agents (US\$) }\end{array}$ & $\begin{array}{l}\text { Market share } \\
\text { by cost (\%) }\end{array}$ \\
\hline \multirow[t]{4}{*}{ Northern } & 2009 & $10,794,022$ & 41,563 & $1,200,447$ & 3.46 & $44,727,733$ & $245,327,406$ & 18.23 \\
\hline & 2010 & $10,852,146$ & 53,085 & $1,352,126$ & 3.93 & $64,066,867$ & $298,340,256$ & 21.47 \\
\hline & 2011 & $10,919,415$ & 74,409 & $1,539,869$ & 4.83 & $80,098,867$ & $335,228,190$ & 23.89 \\
\hline & 2012 & $10,991,480$ & 107,447 & $1,681,041$ & 6.39 & $108,328,729$ & $369,543,105$ & 29.31 \\
\hline \multirow[t]{4}{*}{ Midwestern } & 2009 & $5,201,847$ & 16,182 & 517,142 & 3.13 & $17,550,735$ & $105,008,551$ & 16.71 \\
\hline & 2010 & $5,199,849$ & 22,116 & 587,463 & 3.76 & $25,919,867$ & $130,844,276$ & 19.81 \\
\hline & 2011 & $5,203,796$ & 28,424 & 641,058 & 4.43 & $31,768,038$ & $148,131,812$ & 21.45 \\
\hline & 2012 & $5,215,948$ & 41,136 & 691,949 & 5.94 & $45,052,173$ & $168,569,414$ & 26.73 \\
\hline \multirow[t]{4}{*}{ Southern } & 2009 & $6,446,720$ & 26,808 & 735,122 & 3.65 & $27,431,583$ & $143,013,766$ & 19.18 \\
\hline & 2010 & $6,433,342$ & 33,836 & 834,331 & 4.06 & $37,988,591$ & $178,074,087$ & 21.33 \\
\hline & 2011 & $6,422,584$ & 45,262 & 904,722 & 5.00 & $48,387,511$ & $201,906,589$ & 23.97 \\
\hline & 2012 & $6,422,531$ & 65,905 & 983,272 & 6.70 & $66,284,539$ & $223,610,507$ & 29.64 \\
\hline \multirow[t]{4}{*}{ Eastern } & 2009 & 573,461 & 1,255 & 52,193 & 2.40 & $1,872,532$ & $9,729,754$ & 19.25 \\
\hline & 2010 & 569,478 & 1,736 & 60,197 & 2.88 & $2,248,464$ & $12,178,410$ & 18.46 \\
\hline & 2011 & 565,128 & 2,415 & 66,179 & 3.65 & $2,951,519$ & $14,101,363$ & 20.93 \\
\hline & 2012 & 561,442 & 3,047 & 68,875 & 4.42 & $3,493,182$ & $14,396,745$ & 24.26 \\
\hline \multirow[t]{4}{*}{ Outer Islands } & 2009 & 103,722 & 1 & 2,431 & 0.04 & 53 & 170,837 & 0.03 \\
\hline & 2010 & 107,308 & 0 & 3,261 & 0.00 & 0 & 316,458 & 0.00 \\
\hline & 2011 & 113,989 & 1 & 3,654 & 0.03 & 649 & 387,676 & 0.17 \\
\hline & 2012 & 124,421 & 26 & 4,539 & 0.57 & 17,180 & 481,335 & 3.57 \\
\hline
\end{tabular}

$\pi$ targeted therapies; Market share by prescription volume of targeted therapies $(\%)=$ number of prescription of targeted therapies for the region/number of prescription of all antineoplastic agents for the same region; Market share by costs of targeted therapies (\%) $=$ cost of targeted therapies for the region/cost of all antineoplastic agents for the same region 


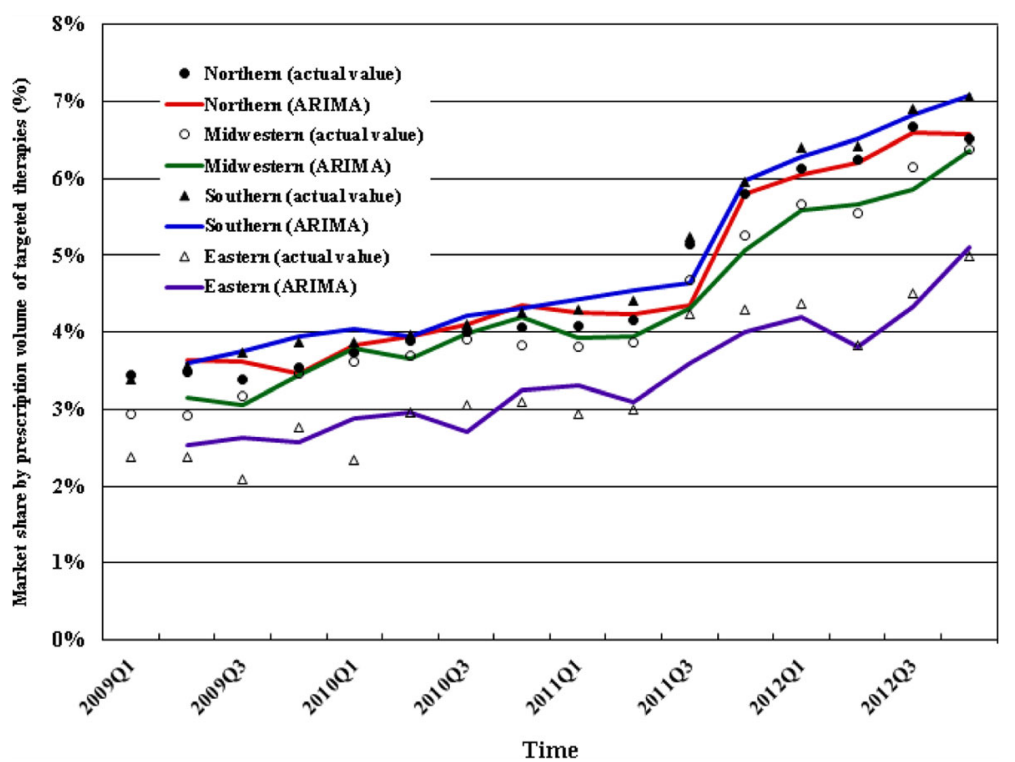

Fig. 1 2009-2012 trend in market share of targeted therapies by prescription volume among total antineoplastic agents by region in Taiwan

share of targeted therapies by prescription volume rose rapidly from $3.39 \%$ in the first quarter of 2009 to $7.05 \%$ in the fourth quarter of 2012. Figure 2 shows 2009-2012 trends in market share by costs by region. In the southern region (region with the highest rate in 2012), the quarterly market share by costs of targeted therapies rose rapidly from $18.51 \%$ in the first quarter of 2009 to $32.19 \%$ in the fourth quarter of 2012 .

\section{Discussion}

Our present study is the first study that estimated the longitudinal trend in use and costs of antineoplastic agents including targeted therapies for cancer treatment by geographic region in Taiwan. Overall our findings do not indicate a significant association between region and use of antineoplastic drugs or use of targeted therapies, after controlling for confounders. Our results suggest an association between region and costs of antineoplastic drugs but we did not find an association between region and costs of targeted therapies. We observed small differences in population-adjusted use of all antineoplastic drugs and a 2 -fold difference in use of targeted therapies between regions except the outer islands; the outer islands had substantially lower use of antineoplastic drugs.

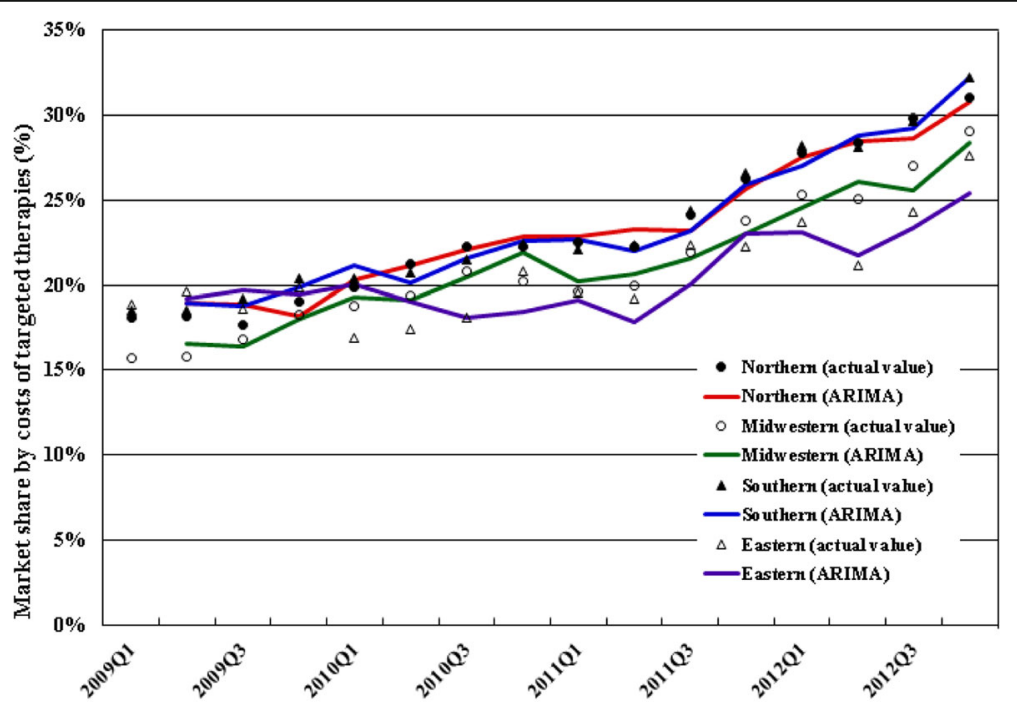

Time

Fig. 2 2009-2012 trend in proportion of costs for targeted therapies among total antineoplastic agents by region in Taiwan 
Previous studies suggested cancer incidence and physician density as determinants of prescription [42, 43]. However, we did not identify these as significant predictors of use and costs of antineoplastic agents or of targeted therapies, after adjusting for covariates including region. It might be because cancer incidence was similar across regions. Access to oncologists might be more important than physician density in the case of access to cancer treatments but there is a lack of information to estimate oncologist density. Our study suggests that average age of cancer patients and percentage of male cancer patients were associated with costs of antineoplastic drugs but they were not associated with use of antineoplastic drugs. These variables might be related to dosing which would impact the overall treatment costs but not the prescription. Furthermore, percentage of male cancer patients was associated with both use and costs of targeted therapies. This is not surprising because lung cancer and colorectal cancer, two of the top three cancers accounting for targeted therapy use have higher prevalence in men [33, 39].

The difference in use of antineoplastic drugs and targeted therapies between the outer islands and other regions were greater than the difference in cancer incidence between these regions. In addition, there was almost no use of targeted therapies until 2012 in the outer islands, suggesting late adoption of new treatments in this region. It may reflect the limited availability of specialist care and hospitals in the outer islands, and patients with cancer in this region may seek and receive cancer treatments in hospitals in other regions instead [44]. To reduce the gap in access to targeted therapies and other antineoplastic drugs between the outer islands and other regions, more efforts might be needed to improve accessibility to care, including diagnosis and treatment of cancer, in the outer islands, or government support for people to travel to the southern region (the region closest to the outer islands) to receive care.

Our findings show that while the market share of targeted therapies by prescription volume increased from 3\% in 2009 to $6 \%$ in 2012 without considering the outer islands, their market share by costs increased from about $20 \%$ in 2009 to about 30\% in 2012. Growing trends in use and costs of targeted therapies for cancer treatment is likely to continue in Taiwan and in all of its regions, which may cause increasing economic burden. In Taiwan, similar to many other countries, health technology assessment to restrict coverage, prior authorization, and higher out-of-pocket costs by patients have been used to relief some economic burden for the national health system. The high cost of targeted therapies may continue to be a barrier to access for patients with cancer $[45,46]$. Increasing economic burden on cancer care overall due to growing use of high-cost targeted therapies challenges the sustainability of the universal insurance system because there might be 'trade-offs' to be made with reimbursements for non-cancer services and treatments. It is important that policymakers revisit the pricing and reimbursement structures for targeted therapies due to their high prices especially because some therapies have little rigorous effectiveness and safety evidence [47-50]. Strategies are needed to ensure patient access to effective health services and treatments without overspending the healthcare budget.

The high costs of cancer targeted therapies and their increasing use for many cancers are issues of growing attention globally because cancer incidence is expected to rise worldwide, from 14 million newly diagnosed patients annually in 2012 to 22 million within the next two decades [51]. With the high costs of cancer care, research should investigate regional inequities in treatment that can results in inequities in health outcomes. Such research is important to inform policy and program implementation to reduce inequities.

There are some limitations to this study. First, this study aimed to examine the recent trends in utilization of antineoplastic drugs particularly cancer targeted therapies by geographic region in Taiwan. We did not analyze the prescribing patterns of antineoplastic drugs and targeted therapies by patient/physician characteristics, and by other environmental factors (number of hospitals, cancer clinics etc). Second, this study examined the trend in overall targeted therapy use, we did not categorize targeted therapies by their pharmacological classification (e.g., protein kinase inhibitors) and indications (types of cancers). Third, our model included physician density by region as a confounder. It would be more precise to estimate and adjust for oncologist density by region; however, this information was not available. Nonetheless, this study should provide a basis for additional research. Further research is needed on geographic variations in cancer screening and diagnosis in Taiwan, and in use of antineoplastic drugs particularly targeted therapies considering other factors such as patient characteristics, physician preferences, and classes of targeted therapies. Studies are also warranted to better understand access to cancer care and treatment in the outer islands.

\section{Conclusion}

This study estimated the nationwide, longitudinal trend in use and costs of antineoplastic drugs by geographic region in Taiwan with a focus on targeted therapies. Overall, we found some geographic variations in use of antineoplastic drugs in Taiwan; use was notably low in the outer islands. Similar to other countries, growing trend in use and costs of targeted therapies for cancer treatment is likely to continue in Taiwan, which may cause increasing economic burden. Strategies might be needed to ensure access to cancer care in each region as economic burden of cancer care increase due to growing use of high-cost targeted therapies. 


\section{Appendix 1}

Table 5 Classification of regions in this study

\begin{tabular}{ll}
\hline Region & Administrative divisions \\
\hline Northern & $\begin{array}{l}\text { Taipei City, New Taipei City, Keelung City, Hsinchu City, } \\
\text { Hsinchu County, Taoyuan City, Yilan County, Miaoli County }\end{array}$ \\
Midwestern & Taichung City, Changhua County, Nantou County \\
Southern & $\begin{array}{l}\text { Tainan City, Yunlin County, Chiayi City, Chiayi County, } \\
\text { Kaohsiung City, Pingtung County }\end{array}$ \\
Eastern & Taitung County, Hualien County \\
Outer & Kinmen County, Penghu County, Lienchiang County \\
islands &
\end{tabular}

\section{Appendix 2}

Table 6 Cancer Incidence, Population Density and Physician Density by year and region

\begin{tabular}{|c|c|c|c|c|}
\hline Region & Year & $\begin{array}{l}\text { Cancer } \\
\text { Incidence (per } \\
100,000 \\
\text { people) }\end{array}$ & $\begin{array}{l}\text { Population } \\
\text { Density (people } \\
\text { per hectare) }\end{array}$ & $\begin{array}{l}\text { Physician Density } \\
\text { (doctor per } \\
100,000 \text { people) }\end{array}$ \\
\hline \multirow[t]{4}{*}{ Northern } & 2009 & 366 & 12.38 & 167.94 \\
\hline & 2010 & 381 & 12.26 & 171.49 \\
\hline & 2011 & 384 & 12.32 & 176.16 \\
\hline & 2012 & 399 & 12.40 & 179.87 \\
\hline \multirow[t]{4}{*}{ Midwestern } & 2009 & 372 & 6.34 & 163.54 \\
\hline & 2010 & 377 & 6.31 & 167.86 \\
\hline & 2011 & 392 & 6.32 & 172.75 \\
\hline & 2012 & 403 & 6.34 & 175.21 \\
\hline \multirow[t]{4}{*}{ Southern } & 2009 & 402 & 6.64 & 159.03 \\
\hline & 2010 & 421 & 6.58 & 163.83 \\
\hline & 2011 & 431 & 6.56 & 167.65 \\
\hline & 2012 & 452 & 6.55 & 170.88 \\
\hline \multirow[t]{4}{*}{ Eastern } & 2009 & 387 & 0.72 & 173.33 \\
\hline & 2010 & 413 & 0.72 & 174.90 \\
\hline & 2011 & 425 & 0.71 & 179.96 \\
\hline & 2012 & 447 & 0.71 & 185.42 \\
\hline \multirow{4}{*}{$\begin{array}{l}\text { Outer } \\
\text { Islands }\end{array}$} & 2009 & 189 & 6.97 & 92.53 \\
\hline & 2010 & 197 & 7.11 & 97.93 \\
\hline & 2011 & 224 & 7.34 & 90.46 \\
\hline & 2012 & 238 & 7.74 & 95.40 \\
\hline
\end{tabular}

\section{Abbreviations}

$\%$ of Male: Percentage of male cancer patients; ANOVA: Analysis of variance; ARIMA: Autoregressive integrated moving average; ATC: Anatomical Therapeutic Chemical; Average Age: Average age of cancer patients; ICD9: International Classification of Diseases, 9th edition; NHIRD: National Health Insurance Research Database; TT: Targeted therapies

\section{Acknowledgements}

Not applicable.

\section{Funding}

Dr. Hsu was supported by Taiwan Ministry of Science and Technology grants (Grant ID: MOST 104-2320-B-006-005, MOST 105-2314-B-006-021). The funders had no role in study design, data collection and analysis, decision to publish, or preparation of the manuscript.

\section{Availability of data and materials}

The authors have obtained nationwide, monthly claims data for cancerrelated antineoplastic agents, from 2009 to 2012, from the Taiwan National Health Insurance Research Database (NHIRD). NHIRD is not publicly available, and it is not permitted external sharing of any of the data elements.

\section{Authors' Contributions}

JCH designed the study, collected data, performed analysis, and drafted the manuscript. SMC reviewed methods and performed analysis. CYL reviewed all data and revised the manuscript critically for intellectual content. All authors approved the final version for submission.

\section{Ethics approval and consent to participate}

Use of the NHIRD for research purpose is exempt from Institutional Review Board (IRB) review in Taiwan. This study was reviewed with exemption and approved by the IRB of National Cheng Kung University Hospital, which is organized and operated according to Taiwan GCP, the applicable laws and regulations.

\section{Consent for publication \\ Not applicable.}

\section{Competing interests}

The authors declare that they have no competing interests.

\section{Publisher's Note}

Springer Nature remains neutral with regard to jurisdictional claims in published maps and institutional affiliations.

\section{Author details}

${ }^{1}$ School of Pharmacy and Institute of Clinical Pharmacy and Pharmaceutical Sciences, College of Medicine, National Cheng Kung University, No.1, Daxue Rd., East Dist., Tainan 70101, Taiwan. ²Department of Statistics, College of Management, National Cheng Kung University, Tainan, Taiwan. ${ }^{3}$ Department of Population Medicine, Harvard Medical School and Harvard Pilgrim Health Care Institute, Boston, MA, USA.

Received: 23 September 2016 Accepted: 20 July 2017

Published online: 02 August 2017

\section{References}

1. Dranitsaris G, Truter I, Lubbe MS, Amir E, Evans W. Advances in cancer therapeutics and patient access to new drugs. Pharmacoeconomics. 2011; 29:213-24.

2. Schoenlein PV, Hou M, Samaddar JS, et al. Downregulation of retinoblastoma protein is involved in the enhanced cytotoxicity of 4-hydroxytamoxifen plus mifepristone combination therapy versus antiestrogen monotherapy of human breast cancer. Int J Oncol. 2007; 31:643-55.

3. Hou N, Huo D. A trend analysis of breast cancer incidence rates in the United States from 2000 to 2009 shows a recent increase. Breast Cancer Res Treat. 2013;138:633-41.

4. Horowitz NS, Miller A, Rungruang B, et al. Does aggressive surgery improve outcomes? Interaction between preoperative disease burden and complex surgery in patients with advanced-stage ovarian cancer: an analysis of GOG 182. J Clin Oncol. 2015;33:937-43.

5. Lippman ME, Krueger KA, Eckert S, et al. Indicators of lifetime estrogen exposure: effect on breast cancer incidence and interaction with raloxifene therapy in the multiple outcomes of raloxifene evaluation study participants. J Clin Oncol. 2001:19:3111-6.

6. Wodarz D, Zauber AG. Cancer: Risk factors and random chances. Nature. 2015;517:563-4.

7. Fedewa SA, Sauer AG, Siegel RL, Jemal A. Prevalence of Major Risk Factors and Use of Screening Tests for Cancer in the United States. Cancer Epidemiol Biomarkers Prev. 2015;24:637-52. 
8. Perdue DG, Haverkamp D, Perkins C, Daley CM, Provost E. Geographic variation in colorectal cancer incidence and mortality, age of onset, and stage at diagnosis among American Indian and Alaska Native people, 19902009. Am J Public Health. 2014;104(Suppl 3):S404-14.

9. Steliarova-Foucher E, Stiller C, Kaatsch P, et al. Geographical patterns and time trends of cancer incidence and survival among children and adolescents in Europe since the 1970s (the ACCISproject): an epidemiological study. Lancet. 2004;364:2097-105.

10. Ess S, Savidan A, Frick H, et al. Geographic variation in breast cancer care in Switzerland. Cancer Epidemiol. 2010;34:116-21.

11. Christian WJ, Huang B, Rinehart J, Hopenhayn C. Exploring geographic variation in lung cancer incidence in Kentucky using a spatial scan statistic: elevated risk in the Appalachian coal-mining region. Public Health Rep. 2011;126:789-96.

12. Lai SM, Zhang KB, Uhler RJ, Harrison JN, Clutter GG, Williams MA. Geographic variation in the incidence of colorectal cancer in the United States, 1998-2001. Cancer. 2006;107:1172-80.

13. Chiou ST, Lu TH. Changes in geographic variation in the uptake of cervical cancer screening in Taiwan: possible effects of "leadership style factor"? Health Policy. 2014;114:64-70.

14. Smieliauskas F, MacMahon H, Salgia R, Shih YC. Geographic variation in radiologist capacity and widespread implementation of lung cancer $C T$ screening. J Med Screen. 2014;21:207-15.

15. Lu SN, Su WW, Yang SS, et al. Secular trends and geographic variations of hepatitis B virus and hepatitis C virus-associated hepatocellular carcinoma in Taiwan. Int J Cancer. 2006;119:1946-52.

16. McWilliams JM, Dalton JB, Landrum MB, Frakt AB, Pizer SD, Keating NL. Geographic variation in cancer-related imaging: Veterans Affairs health care system versus Medicare. Ann Intern Med. 2014;161:794-802.

17. Su WW, Chen $\mathrm{CH}$, Lin HH, et al. Geographic variations of predominantly hepatitis $C$ virus associated male hepatocellular carcinoma townships in Taiwan: identification of potential high HCV endemic areas. Hepatol Int. 2009:3:537-43

18. Guadagnolo BA, Liu CC, Cormier JN, Du XL. Evaluation of trends in the use of intensity-modulated radiotherapy for head and neck cancer from 2000 through 2005: socioeconomic disparity and geographic variation in a large population-based cohort. Cancer. 2010;116:3505-12.

19. Cary KC, Punnen S, Odisho AY, Litwin MS, Saigal CS, Cooperberg MR. Nationally representative trends and geographic variation in treatment of localized prostate cancer: the Urologic Diseases in America project. Prostate Cancer Prostatic Dis. 2015;18:149-54.

20. Deleyiannis FW, Weymuller EA Jr, Garcia I, Potosky AL. Geographic variation in the utilization of esophagoscopy and bronchoscopy in head and neck cancer. Arch Otolaryngol Head Neck Surg. 1997;123:1203-10.

21. Reames BN, Sheetz KH, Waits SA, Dimick JB, Regenbogen SE. Geographic variation in use of laparoscopic colectomy for colon cancer. J Clin Oncol. 2014:32:3667-72.

22. Chen $\mathrm{CH}$, Su WW, Yang SS, et al. Long-term trends and geographic variations in the survival of patients with hepatocellular carcinoma: analysis of 11,312 patients in Taiwan. J Gastroenterol Hepatol. 2006;21:1561-6.

23. Andia ME, Hsing AW, Andreotti G, Ferreccio C. Geographic variation of gallbladder cancer mortality and risk factors in Chile: a population-based ecologic study. Int J Cancer. 2008;123:1411-6.

24. Kohne $\mathrm{CH}$, Lenz $\mathrm{HJ}$. Chemotherapy with targeted agents for the treatment of metastatic colorectal cancer. Oncologist. 2009;14:478-88.

25. Mahalingam D, Mita A, Mita MM, Nawrocki ST, Giles FJ. Targeted therapy for advanced non-small cell lung cancers: historical perspective, current practices, and future development. Curr Probl Cancer. 2009;33:73-111.

26. Mok TS, Wu YL, Thongprasert S, et al. Gefitinib or carboplatin-paclitaxel in pulmonary adenocarcinoma. N Engl J Med. 2009;361:947-57.

27. Burotto M, Manasanch EE, Wilkerson J, Fojo T. Gefitinib and erlotinib in metastatic non-small cell lung cancer: a meta-analysis of toxicity and efficacy of randomized clinical trials. Oncologist. 2015;20:400-10.

28. Biswas B. Erlotinib versus docetaxel as second- or third-line therapy in patients with advanced non-small-cell lung cancer in the era of personalized medicine. J Clin Oncol. 2015;33:524.

29. Song Z, Zhang Y. Efficacy of gefitinib or erlotinib in patients with squamous cell lung cancer. Arch Med Sci. 2015;11:164-8.

30. Lu CY, Srasuebkul P, Drew AK, Chen K, Ward RL, Pearson SA. Trastuzumab therapy in Australia: which patients with HER2+ metastatic breast cancer are assessed for cardiac function? Breast. 2013;22:482-7.
31. Lu CY, Srasuebkul P, Drew AK, Ward RL, Pearson SA. Positive spillover effects of prescribing requirements: increased cardiac testing in patients treated with trastuzumab for HER2+ metastatic breast cancer. Intern Med J. 2012;42: 1229-35.

32. Hsu JC, Lu CY. The evolution of Taiwan's National Health Insurance drug reimbursement scheme. Daru. 2015:23:15.

33. Hsu JC, Lu CY. Longitudinal trends in use and costs of targeted therapies for common cancers in Taiwan: a retrospective observational study. BMJ Open. 2016:6:e011322

34. Hsu JC, Gonzalez-Gonzalez LA, Lu VH, Lu CY. Longitudinal trends in use of targeted therapies for treatment of malignant neoplasms of the eye: a population-based study in Taiwan. BMJ Open. 2016;6:e010706.

35. Liu SZ, Romeis JC. Assessing the effect of Taiwan's outpatient prescription drug copayment policy in the elderly. Med Care. 2003;41:1331-42.

36. Hsu JC, Lu CY, Wagner AK, Chan KA, Lai MS, Ross-Degnan D. Impacts of drug reimbursement reductions on utilization and expenditures of oral antidiabetic medications in Taiwan: An interrupted time series study. Health Policy. 2013;

37. Hsu JC, Ross-Degnan D, Wagner AK, et al. Utilization of oral antidiabetic medications in Taiwan following strategies to promote access to medicines for chronic diseases in community pharmacies. J Pharm Policy Pract. 2015;8:15.

38. Department of Statistics, Taiwan Ministry of Interior, website: http://www.ris gov.tw/zh_TW/346. Accessed 28 July 2017.

39. Report CRA. Taiwan. Health Promotion Administration. Ministry of Health and Welfare. 2011;2014

40. Mills TC. Time Series Techniques for Economists. Cambridge University Press. 1990;

41. Asteriou DH, Stephen G. ARIMA Models and the Box-Jenkins Methodology, Applied Econometrics (Second ed.) Palgrave MacMillan 2011:265-86.

42. Domenighetti G, Casabianca A. Health care economics, uncertainty and physician-induced demand. Schweiz Med Wochenschr. 1995;125:1969-79.

43. Mullins RJ, Clark S, Camargo CA Jr. Regional variation in infant hypoallergenic formula prescriptions in Australia. Pediatr Allergy Immunol. 2010;21:e413-20.

44. Kreng VB, Yang CT. The equality of resource allocation in health care under the National Health Insurance System in Taiwan. Health Policy. 2011;100:203-10

45. O'Dowd A. Watchdog set to reject four drugs for kidney cancer on the NHS BMJ. 2008;337:a1262

46. Wahlstera P, Scahillb S, Lu CY, Babar Z-U-D. Barriers to access and use of high cost medicines: A review. Health Policy and Technology. 2015;4:191-214.

47. Kantarjian HM, Fojo T, Mathisen M, Zwelling LA. Cancer drugs in the United States: Justum Pretium-the just price. J Clin Oncol. 2013;31:3600-4.

48. Lu CY, Williams K, Day R, March L, Sansom L, Bertouch J. Access to high cost drugs in Australia. BMJ. 2004;329:415-6.

49. Hall WD, Ward R, Liauw WS, Lu CY, Brien JA. Tailoring access to high cost, genetically targeted drugs. Med J Aust. 2005;182:607-8.

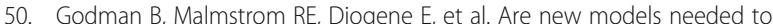
optimize the utilization of new medicines to sustain healthcare systems? Expert Rev Clin Pharmacol. 2015;8:77-94.

51. WHO website: http://www.who.int/mediacentre/factsheets/fs297/en/. Accessed 28 July 2017

\section{Submit your next manuscript to BioMed Central and we will help you at every step:}

- We accept pre-submission inquiries

- Our selector tool helps you to find the most relevant journal

- We provide round the clock customer support

- Convenient online submission

- Thorough peer review

- Inclusion in PubMed and all major indexing services

- Maximum visibility for your research

Submit your manuscript at www.biomedcentral.com/submit 